\title{
MeCANISMOS DE ACCIÓN DEL RECEPTOR DE hidROCARBUROS DE ARILOS EN EL METABOLISMO DEL BENZO[A]PIRENO Y EL DESARROLLO DE TUMORES
}

\author{
Gerardo Vázquez-Gómez, Julieta Rubio-Lightbourn \\ y Jesús Javier Espinosa-Aguirre \\ Depto. de Medicina Genómica y Toxicología Ambiental, Instituto de Investigaciones \\ Biomédicas, Universidad Nacional Autónoma de México, Ciudad Universitaria, \\ Deleg. Coyoacán, C.P. 04510, México, D.F., México. E-mail: jjea99@gmail.com
}

\begin{abstract}
Resumen
El benzo[a]pireno (b[a]p), es un hidrocarburo aromático policíclico (PAH) producto de combustiones incompletas de materia orgánica. Es considerado como carcinógeno debido a que los metabolitos derivados de su biotransformación, como el benzo [a] pireno diol epóxido (b[a]pDE), tienen propiedades mutagénicas y carcinogénicas. El b[a]p es metabolizado por las enzimas citocromos P450 1Al (CYP1A1) y el citocromo P450 1B1 (CYP1B1 ) cuya expresión es inducida por la vía de señalización del receptor de hidrocarburos de arilo (AhR). Algunos estudios sugieren que el AhR es capaz de modular otros procesos celulares, además de la desintoxicación de xenobióticos como el desarrollo, diferenciación, proliferación, respuesta inmune, promoción del cáncer y apoptosis. Esto mediante la modulación de vías de señalización mediadas por proteínas cinasas como la del receptor del factor de crecimiento epidermal (EGFR, por sus siglas en inglés). Sin embargo, no es clara la función del AhR en estos procesos ni cómo el AhR es capaz de interactuar con otras vías de señalización. Las alteraciones celulares inducidas por b [a]p son complejas y pueden estar mediadas por más de una vía de señalización y la activación de múltiples genes, por lo que es esencial saber qué vías están involucradas en el metabolismo de los PAH para una mejor comprensión de las bases moleculares de enfermedades como el cáncer.
\end{abstract}

Palabras Clave: AhR, benzo[a]pireno, cáncer de pulmón, EGFR, PAH.

\section{Action mechanisms of aryl hydrocarbon receptor in metabolism of benzo [a] pyrene and tumor development}

\begin{abstract}
Benzo[a]pyrene (b[a]p), is a polycyclic aromatic hydrocarbon (PAH) product of incomplete combustion of organic matter. $\mathrm{B}[\mathrm{a}] \mathrm{p}$ is considered as a carcinogen due to the mutagenic and carcinogenic properties of its biotransformation derivatives, such as benzo[a]pyrene diol epoxide (b[a]pDE). B [a]p is metabolized by cytochrome P450 enzymes 1Al (CYP1A1) and IBI (CYP1B1), whose expression is regulated by the aryl hydrocarbon receptor (AhR) signaling pathway. Studies suggest that AhR is involved in the regulation of other cellular processes, in addition to detoxification of xenobiotics, such as development, differentiation, proliferation, immune response, cancer development, and apoptosis, by modulating signaling pathways mediated by protein kinases such as the epidermal growth factor (EGFR). However it is not clear the role of AhR in these processes nor the mechanisms of AhR interaction with other signaling pathways. Cellular changes induced by b[a]p are complex and may be mediated by more than one signaling pathway and by the activation of multiple genes, so it is essential to know which pathways are involved in the metabolism of PAHs for a better understanding of the molecular basis of diseases such as cancer.
\end{abstract}

Key Words: AhR, benzo[a]pyrene, lung cancer, EGFR, PAH.

Nota: Artículo recibido el 23 de junio de 2015 y aceptado el 19 de enero de 2016. 


\section{INTRODUCCIÓN}

1 os hidrocarburos aromáticos policíclicos (PAH, por sus siglas en inglés) son compuestos químicos conformados por dos o más anillos aromáticos fusionados. Son producto de combustiones incompletas de combustibles fósiles, madera, carbón y tabaco, principalmente. Son componentes importantes del material particulado de 2.5 micras y 10 micras de tamaño (PM 2.5 y PM 10, respectivamente) los cuales se han relacionado con alteraciones respiratorias. El benzo[a]pireno $(b[a] p)$ es un PAH considerado como carcinógeno y está relacionado con la etiología de cáncer de pulmón ${ }^{1}$. Este compuesto es metabolizado mediante la vía de señalización del receptor de hidrocarburos de arilo (AhR, por sus siglas en inglés). Los efectos carcinogénicos del $b[a] p$ pueden ser explicados, en términos generales, por dos mecanismos: la vía genómica y la vía no genómica. La primera consiste en la inducción de genes que codifican enzimas que participan en la bioactivación delb[a]p. Por ejemplo, en presencia de b[a]p la enzima citocromo P450 1A1 (CYP1A1) produce dioles epóxidos del $b[a] p$ que son capaces de reaccionar con el ADN produciendo lesiones premutagénicas. Este mecanismo explica las observaciones de Vogelstein y cols. en donde células tumorales de pulmón presentan diez veces más mutaciones que otros tipos de tumores ${ }^{2}$. El segundo mecanismo tiene que ver con la participación del AhR en la estimulación, promoción y progresión de tumores, mediante la alteración de las vías de señalización relacionadas con la proliferación celular y del sistema inmune. Es probable que estos efectos estén mediados por la intercomunicación de la vía genómica y la no genómica. Sin embargo, el papel del AhR en esta intercomunicación no es muy conocido. No obstante, existen trabajos que podrían ayudar a comprender su papel en la producción de tumores, destacando aquellos donde se sugiere la interacción de la vía de señalización del AhR con la vía de receptores tipo ErbB, como el receptor del factor de crecimiento epidermal (EGFR). Por lo que el presente trabajo se enfoca en revisar los trabajos que muestran evidencias de la intercomunicación entre estas dos vías de señalización inducidas bajo el estímulo de los PAH.

\section{El RECEPTOR DE HIDROCARbUROS DE ARILO (AhR)}

El receptor de hidrocarburos de arilos (AhR) es un factor de transcripción citoplasmático perteneciente a la familia de los factores de transcripción con dominio bHLH-PAS (basic helix loop helix-PER ARNT-SIM). ${ }^{3,4}$ Esta familia de proteínas desempeña un papel importante en diversos procesos celulares como desarrollo, adaptación a hipoxia, control del ciclo circadiano y metabolismo de xenobióticos ${ }^{5}$. Estas proteínas se dividen en dos clases: Clase I $(\alpha)$ y clase II $(\beta)$. La expresión de las proteínas de la clase I, generalmente está restringida a un tejido o es regulada por una señal y forman heterodímeros sólo con las proteínas de la clase II, mientras que la clase II, es ubicua o su expresión no está sometida a regulación y puede formar homodímeros con proteínas de su misma clase. ${ }^{6}$ Por ejemplo, la expresión del AhR o el factor inducible por hipoxia alfa $(\mathrm{HIF}-\alpha)$, en humano, es inducible. Estas proteínas dimerizan con el translocador nuclear del receptor de arilos (ARNT, por sus siglas en inglés), el cual, por lo general es ubicuo o su expresión no está sometida a regulación (Figura 1).

El AhR fue uno de los primeros factores de transcripción perteneciente a la familia bHLH en ser descubierto y estudiado. Su cADN fue clonado por primera vez por Ema et al. ${ }^{7}$ en 1992 y por Burbach et al. ${ }^{8}$ en el mismo año. El gen fue caracterizado por Schmidt et al. ${ }^{9}$ y desde entonces se han clonado homólogos del AhR de diferentes especies; por ejemplo, en humano (Homo sapiens) $)^{10}$, ratón (Mus musculus) $)^{7,8,11,12}$, rata (Rattus norvergicus; Sprague-Dawley) ${ }^{13}$, Hamster (Mesocrisetus auratus) ${ }^{14}$, delfín (Lagenorhynchus auratus $)^{15} \mathrm{y}$ foca (phoca sibirica) $)^{16}$. También han sido clonadas secuencias de vertebrados no mamíferos como aves $^{17,18}$, anfibios ${ }^{18}$, peces cartilaginosos ${ }^{19,20}$, lampreas ${ }^{19}$ e invertebrados como bivalvos (Mya arenaria) $)^{21}$, nematodos (Caenorhabditis elegans) $)^{19}$ y la mosca de la fruta (Drosophila melanogaster $)^{22}$. El gen que codifica para el AhR en humano se localiza en el brazo corto del cromosoma 7 en la posición $15^{23}$ y se expresa principalmente en pulmón, timo, hígado y riñón ${ }^{24}$.

El AhR en mamíferos presenta tres dominios funcionales. Un dominio altamente conservado bHLH que consiste de 4 a 6 aminoácidos ácidos en el extremo amino terminal. Este dominio tiene la función de interacción con el ADN. El segundo dominio son dos repetidos de los dominios PAS (PAS A y PAS B) cada uno conteniendo aproximadamente 110 aminoácidos. Análisis estructurales, bioquímicos y de interacción de proteínas sugieren que el dominio PAS A está relacionado con la dimerización mientras que PAS B funciona como dominio de señalización ${ }^{6,25}$. El tercer domino $(\mathrm{Q})$ es esencial en la transactivación, es un dominio poco conservado y se localiza en el extremo carboxilo terminal ${ }^{26}$ (Figura 2).

\section{Vía de señalización del AhR}

La activación del AhR está dada por la unión de un ligando. Estos ligandos son principalmente xenobióticos, de naturaleza hidrofóbica y con estructura plana. Pueden ser de origen natural, como el caso de los metabolitos secundarios de plantas o producto de combustiones incompletas, como es el caso de los PAH. Pueden ser también de origen sintético como los hidrocarburos aromáticos halogenados (HAH) o el 2,3,7,8-tetraclorodibenzo$p$-dioxina (TCDD). Además de unirse a xenobióticos, se ha reportado que el AhR es capaz de unir compuestos endógenos como la bilirrubina ${ }^{27}$, lipoxina $\mathrm{A} 44^{28}$ y derivados del triptófano ${ }^{29-31}$.

El AhR en estado latente (sin un ligando unido) se localiza predominantemente anclado en el citoplasma de la célula como parte de un complejo heterodimérico 9S. Este complejo está formado por un dímero de la proteína de choque térmico 90 (Hsp90), una proteína de choque térmico con un peso de 23 $\mathrm{KDa}(\mathrm{p} 23)$ y una proteína de interacción con AhR parecida a 


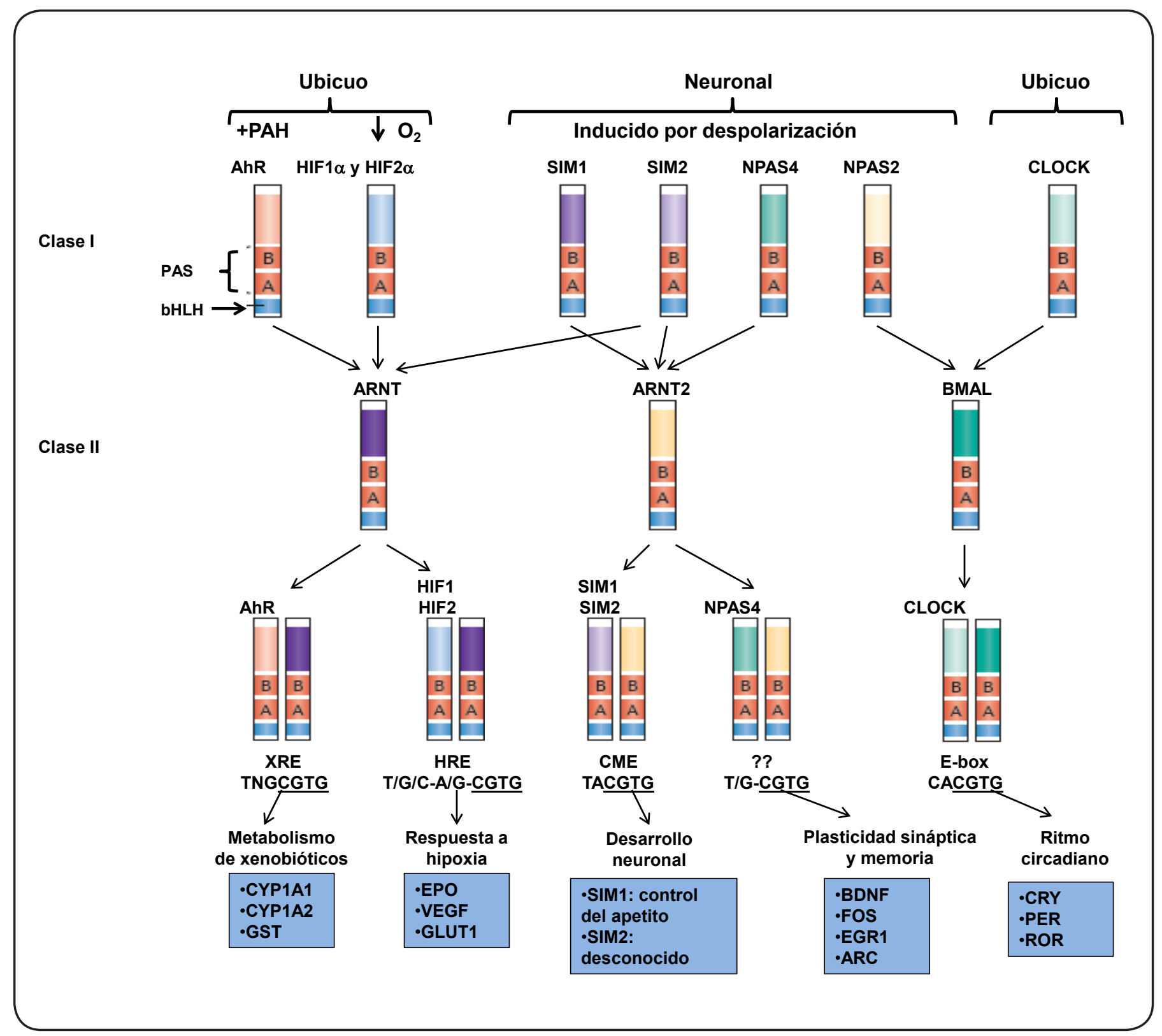

Figura 1. Estructura y función de las proteínas de la clase I y II de la familia bHLH-PAS. Se muestran ejemplos de los factores de transcripción heterodiméricos bHLH-PAS. Los dímeros son formados por la interacción entre los factores de la clase I y los factores de la clase II (como lo indican las flechas). La expresión de los factores de la clase I posiblemente está restringida a un tejido (como la proteína neuronal con dominio PAS (NPAS)) o se active en respuesta de un estímulo, como el AhR. Los heterodímeros se unen a secuencias específicas en el ADN y regulan la expresión de genes blanco. De este modo, son capaces de controlar diversos procesos celulares en el desarrollo, homeostasis celular o en procesos celulares en respuesta a un estrés fisiológico. Los factores de transcripción pertenecientes a la clase II son capaces de formar dímeros con más de un factor de la clase I aunque algunas combinaciones pueden ser limitadas in vivo. Por ejemplo, la expresión del factor ARNT2 está restringida a neuronas y es funcional sólo cuando dimeriza con el factor SIM1. Otro ejemplo es el AhR, este factor unido a un ligando puede dimerizar con ARNT o ARNT2 in vitro. Sin embargo, sólo los dímeros AhR/ARNT pueden activar la transcripción de sus genes blanco ${ }^{32}$. Elementos que se muestran en la figura: ARC, proteína asociada al citoesqueleto regulada por actividad; BDNF, factor neurotrófico derivado del cerebro; CME, elemento central de la línea media; CLOCK (por sus siglas en inglés), Circadian Locomotor Output Cycles Kaput; CRY, criptocromos; CYP1A1, citocromo P4501A1; EGR1, proteína de respuesta de crecimiento temprano 1; EPO, eritropoyetina; GLUT 1, transportador de glucosa 1; GST, glutatión S-transferasa; HRE, elemento de respuesta a hipoxia; PER, proteína homóloga del ciclo circadiano; ROR, receptor huérfano relacionado al ácido retinoico; SIM proteína single-minded; VEGF, factor de crecimiento endotelio vascular; XRE, elemento de respuesta a xenobióticos. Modificado de Bersten et al. ${ }^{33}$ 


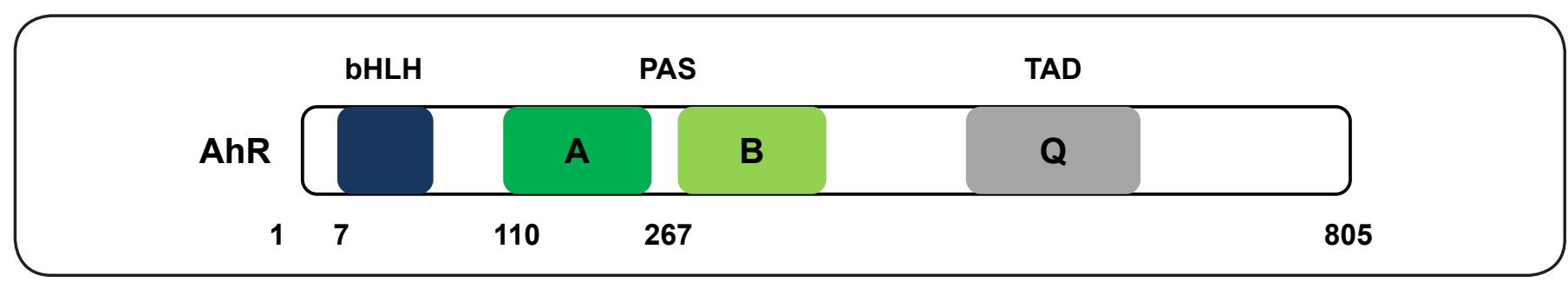

Figura 2. Estructura del AhR de humano. Se muestran los dominios funcionales $A$ y $B$, secuencias de repetidos de nucleótidos presentes en el dominio PAS; bHLH, dominio con estructura básica de hélice-bucle-hélice; dominio de unión de la proteína de choque térmico de $90 \mathrm{KDa}$ (Hsp90); Q, dominio rico en glutamina; TAD, dominio de activación transcripcional; LBD, dominio de unión a ligando. Los números representan los aminoácidos de la proteína. Modificado de Wu et al. ${ }^{6}$

la inmunofilina (AIP), también conocida como XAP2 o Ara9. Adicionalmente, se ha descrito la presencia de otras proteínas citosólicas incluyendo la chaperona (Cdc37) y una cinasa de tirosina (c-src) ${ }^{34,35}$ (Figura 3).

La activación del AhR se caracteriza por su translocación al núcleo y la disociación del complejo al cual está unido. Una vez en el núcleo, el AhR, formará un heterodímero con la proteína translocador nuclear del receptor de arilos (ARNT). Este heterodímero AhR/ARNT interaccionará con proteínas acetil transferasas de histonas y factores remodeladores de cromatina, lo que resulta en la unión del complejo AhR/ARNT a una secuencia de ADN consenso (GCGTGA) conocida como elemento de respuesta a xenobióticos o elementos de respuesta a dioxinas (XRE, DRE). Esta secuencia está localizada aproximadamente a $1 \mathrm{~Kb}$ río arriba de sus genes blanco ${ }^{36}$. Dentro de estos genes se incluyen aquéllos que codifican enzimas de la fase I del metabolismo de xenobióticos, representada por citocromos P450 (CYP450) y de la fase II la cual incluye a las glutatión S-transferasas (GST) y las UDP glucuronil transferasas (UGT). Los genes de la fase I, regulados por el AhR/ARNT, sólo incluyen a los miembros de la familia CYP1 de los CYP450 (CYP1A1, CYP1A2, CYP1B1) ${ }^{37,38}$. La expresión de otros CYP450, como CYP3 y CYP4, está regulada por los receptores nucleares CAR, PXR y PPAR los cuales dimerizan con el receptor $\mathrm{RXR}^{39}$.

De acuerdo con Hahn ${ }^{15}$, la habilidad delAhR de unir xenobióticos y mediar una respuesta adaptativa que involucra la inducción de enzimas metabolizadoras de xenobióticos, puede ser una función exclusiva de los vertebrados debido a que en los invertebrados el AhR no es capaz de unir xenobióticos. En estos últimos, el AhR participa en procesos de desarrollo, por ejemplo, en $D$. melanogaster es esencial para el correcto desarrollo de los segmentos distales de las antenas y las alas ${ }^{22,40}$ mientras que en C. elegans, el AhR participa en la diferenciación neuronal ${ }^{41,42}$.

\section{Regulación de la vía del AhR}

Desde su descubrimiento en mamíferos se pensó que la única función del AhR era la de participar en la respuesta adaptativa al estrés celular, actuando como un sensor de señales endógenas o inducidas por xenobióticos. Sin embargo, existe evidencia experimental que vincula al AhR con la alteración de diversos procesos celulares como proliferación celular, apoptosis, diferenciación, promoción de tumores, reproducción y respuesta inmune $e^{43}$. Ésto sugiere que además de ser un sensor de xenobióticos, el AhR es esencial en la homeostasis celular. No obstante, los mecanismos por los cuales desempeña este último papel son poco conocidos. Por otro lado, la capacidad de respuesta del AhR difiere entre especies y tipo celular, lo que puede ser un indicativo de las posibles interacciones con diferentes vías de señalización y de la complejidad de su papel. Debido a que el AhR está involucrado en diversos procesos celulares, su señalización debe ser estrictamente regulada. Por este motivo, las células han desarrollado diferentes sistemas para evitar una excesiva señalización. Al ser una señal (ligando) el factor regulador de su transcripción, el mecanismo más directo de regular la vía es eliminar la señal. La activación del AhR conlleva a una sobreexpresión de enzimas de la fase I y II del metabolismo de xenobióticos las cuales oxidan y forman derivados de los ligandos, facilitando su remoción por medio de transportadores de membrana dependientes de ATP ${ }^{44}$. Otro mecanismo por el cual la célula es capaz de disminuir la señalización es por medio de la degradación vía proteosoma $26 \mathrm{~S}^{45-47}$. La actividad del AhR también puede ser modulada por la secuencia de exportación nuclear (NES) presente en el AhR. Esta secuencia permite que el AhR, en su forma activa, pueda ser exportado del núcleo hacia el citoplasma y de esa manera, evitar la inducción de la transcripción génica ${ }^{48}$. Por otro lado, la activación del AhR induce la transcripción del represor del AhR (AhRR). Sin embargo, el mecanismo exacto por el cual el AhRR reprime la vía del AhR no es conocida ${ }^{49}$, aunque se ha sugerido que el AhRR es capaz de competir directamente con el AhR in vitro, formando un dímero con el ARNT y, de esta manera, evitar la transcripción de sus genes blanco ${ }^{49}$.

\section{BENZO[A] PIRENO}

Una de las principales moléculas capaces de activar al AhR e inducir su vía de señalización es el b[a]p. Este compuesto fue el primer carcinógeno detectado en el humo del tabaco y fue uno 


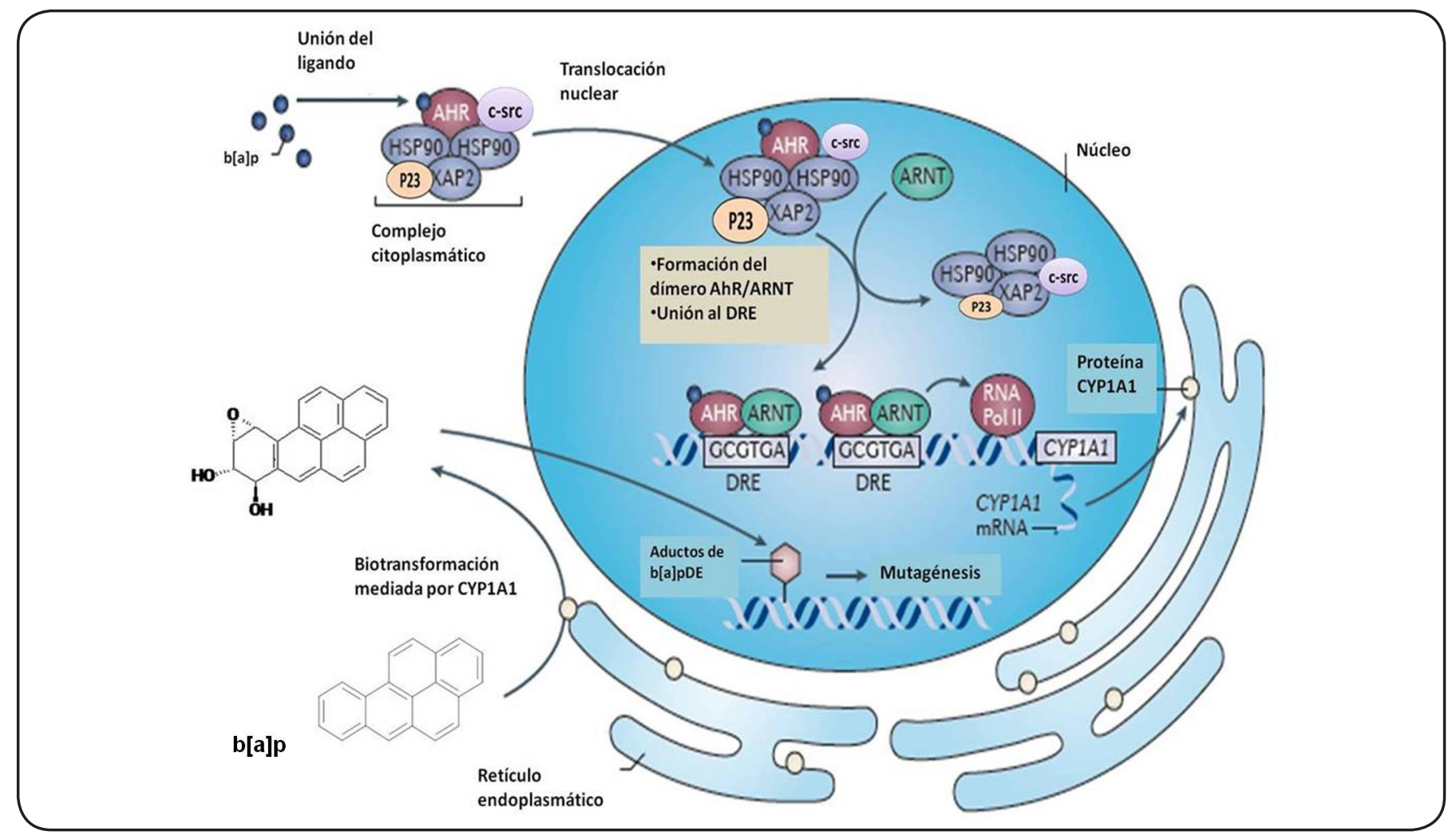

Figura 3. Activación del AhR. El receptor en su forma inactiva (sin un ligando unido) se localiza en el citoplasma celular formando un complejo con un dímero de la proteína de choque térmico 90 (Hsp90), una proteína de choque térmico con un peso de $23 \mathrm{KDa}(\mathrm{P} 23)$ y una proteína de interacción con el AhR parecida a la inmunofilina (AIP), también conocida como XAP2, y una cinasa de tirosina (c-src). Una vez unido su ligando, el complejo AhR se transloca al núcleo y forma un heterodímero con la proteina ARNT. Este heterodímero es capaz de unirse a los XRE (GCGTGA) y reclutar coactivadores y asífavorecer la transcripción de sus genes blanco como el CYP1A1. Este citocromo metabolizará al b[a]p en intermediarios que pueden interactuar con el ADN para formar aductos iniciando así un proceso carcinogénico. Modificado de Murray et al. ${ }^{50}$

de los carcinógenos más estudiados durante el siglo pasado ${ }^{51}$ (Figura 4). El b[a]p es un hidrocarburo policíclico aromático formado por la combustión incompleta de materia orgánica, es un contaminante persistente y ubicuo en el ambiente. Las principales fuentes de exposición ab[a]p son las carnes cocinadas al carbón, la quema de combustibles fósiles, la quema de leña y el humo de tabaco ${ }^{52}$. Posterior a la exposición a b[a]p, éste puede distribuirse en distintos órganos como el hígado, riñón y sangre $^{53-56}$. Por otro lado, la naturaleza lipofílica del $\mathrm{b}[\mathrm{a}] \mathrm{p}$ favorece su almacenamiento en tejidos grasos incluyendo glándulas mamarias y médula ósea. También se sabe que el $b[a] p$ es capaz de cruzar la barrera hematoencefálica y la placenta ${ }^{57}$. A pesar de que el $b[a] p$ puede metabolizarse en diversos órganos, se ha reportado que los metabolitos de b[a]p se concentran principalmente en el pulmón, específicamente en el tejido bronco epitelial ${ }^{58}$. Las células epiteliales del tracto respiratorio son las primeras en estar en contacto con las partículas de $b[a] p$ presente en el ambiente. Se estima que una persona fumadora puede estar expuesta a concentraciones promedio de 20-40 ng de $b[a] p$ por cigarro ${ }^{59}$.

\section{Metabolismo de b[A]P dependiente del AhR}

El metabolismo de $b[a] p$ tiene especial importancia ya que aunque no es tóxico per se, su efecto carcinógeno reside en la formación de metabolitos primarios y secundarios potencialmente tóxicos que son capaces de interactuar con constituyentes celulares e inducir un daño celular. Esto mediante la vía de señalización del $\mathrm{AhR}^{60}$ la cual involucra la inducción de genes que codifican enzimas de las fases I y II del metabolismo de xenobióticos.

En la primera fase, el b[a]p es oxidado por elCYP1A1 y produce (+)- y (-)-b[a]p- 7, 8-óxidos, teniendo una tasa de conversión mucho más alta del enantiómero (+)-. Posteriormente, la epóxido hidrolasa (EH) hidroliza estos óxidos y se forman (-)- y (+)-b[a]p-7, 8-dioles, que son oxidados una vez más por CYP1A1 para formar (-)-b[a]p-7,8-diol-9, 10-epóxido-1, (+)-b[a]p-7,8-diol-9, 10-epóxido-2, (+)-b[a]p-7,8-diol-9, 10-epóxido-1 y(-)-b[a]p-7,8-diol-9, 10-epóxido-2 (b[a]pDE) ${ }^{61-62}$, como se muestra en la Figura 5. 


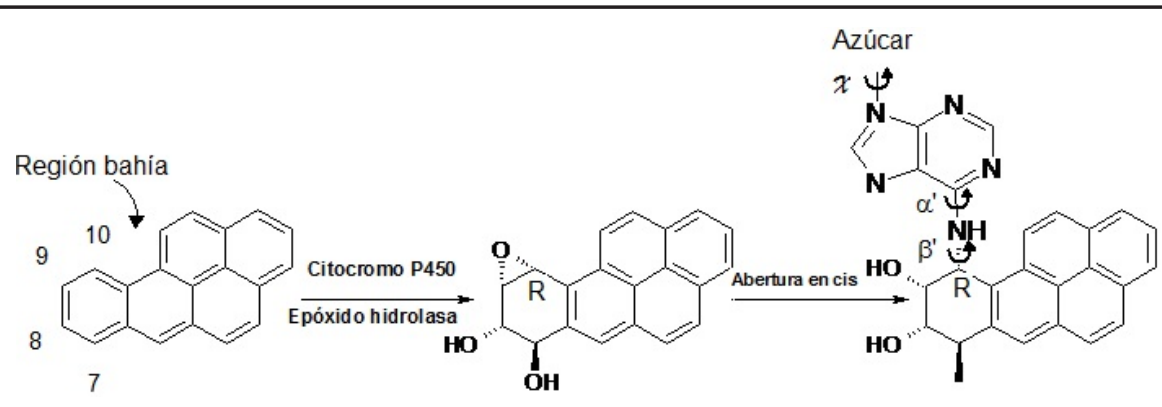

Figura 4. Estructura química del b[a]p. Se representa la formación del metabolito benzo[a]pireno diol epóxido (b[a]pDE) mediada por CYP450 y epóxido hidrolasas, así como la formación de un aducto en el ADN dado por la apertura en cis del diol epóxido (DE) por el grupo amino del carbono 6 de la adenina. Modificado de Ling et al. ${ }^{63}$

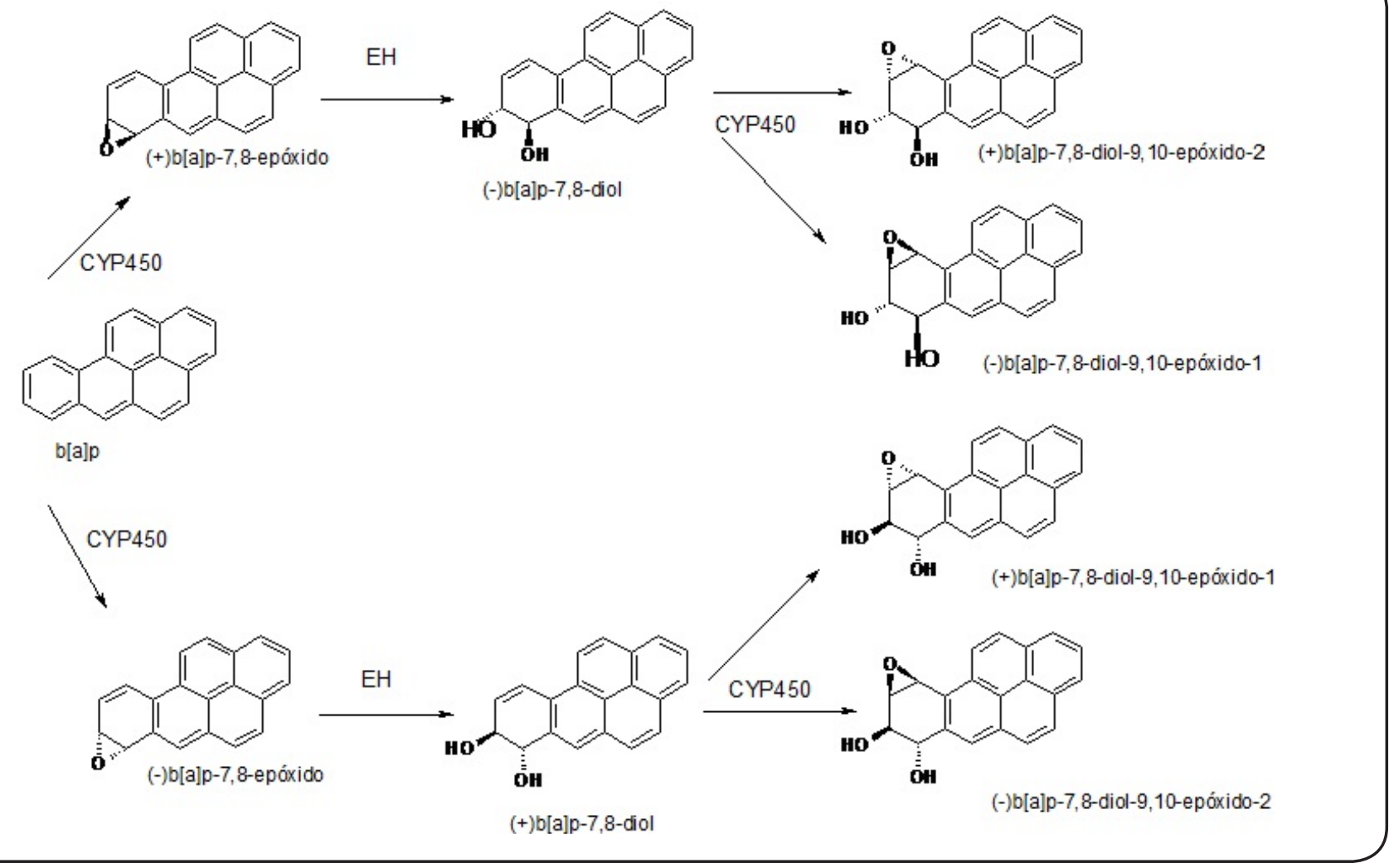

Figura 5. Vía metabólica mediante la cual el b[a]p se bioactiva a b[a]pDE, metabolitos altamente reactivos. Modificado de Shimada ${ }^{64}$.

La fase II consiste en la conjugación de los b[a]pDE generados en la fase I con moléculas polares, y de esta manera evitar su interacción y un posible daño a constituyentes celulares como el ADN. Las enzimas de la fase II que catalizan la conjugación tienen diferente especificidad por sus sustratos. El nivel de expresión depende del tipo de tejido y estados de desarrollo del organismo. Por otro lado, pueden ser inducibles o inhibidas por xenobióticos ${ }^{65}$. Se han descrito diversas enzimas que participan en la fase II, por ejemplo, sulfotransferasas (SULT) ${ }^{66}$, UDPglucuronosiltransferasas (UGT) ${ }^{67,68}$, DT-diaforasas o NAD(P) $\mathrm{H}$ :quinona oxidorreductasas (NQO), NAD(P)H:menadiona reductasas $(\mathrm{NMO})^{69}$, epóxido hidrolasas $(\mathrm{EH})^{70}$, glutatión S-transferasas $(G S T)^{71}$ y N-acetiltransferasas $(\mathrm{NAT})^{72}$. Sin embargo, las GST son las principales enzimas que participan en esta fase ${ }^{73}$. El patrón de distribución y expresión de las GST es complejo, incluso, los diferentes tipos celulares presentes en un 
mismo tejido tienen distintos patrones de expresión. Así mismo, los patrones de distribución interindividual también pueden variar. Por ejemplo, en el humano los patrones de expresión de las GST en el pulmón pueden variar debido a la presencia de polimorfismos en genes que codifican a las enzimas ${ }^{74}$.

Las GST catalizan la conjugación de glutatión (GSH) con b[a] pDE, lo que generalmente incrementa la hidrofobicidad de $\mathrm{b}[\mathrm{a}] \mathrm{pDE}$ y por lo tanto aumenta su excreción por medio de la bilis u orina ${ }^{65}$. Este mecanismo es considerado como la vía de inactivación de $\mathrm{b}[\mathrm{a}] \mathrm{pDE}$ más importante ${ }^{75,76}$. Las tres isoformas de las GST mejor conocidas son las GST $\mu, \theta$ y $\pi$; las isoformas $\mu$ y $\pi$ tienen múltiples sustratos que incluyen al $b[a] p D E$, acroleína y otros carbonilos insaturados generados por peróxidos lipídicos y daño oxidante al $\mathrm{ADN}^{77-79}$. La isoforma de las GST $\mu$ presenta la mayor actividad enzimática en la conjugación de $\mathrm{b}[\mathrm{a}] \mathrm{pDE}$ seguida de las isoformas $\pi$ y $\theta^{80,81}$.

\section{B[A]P COMO CARCINÓGENO}

Como se mencionó anteriormente, el $\mathrm{b}[\mathrm{a}] \mathrm{p}$ es un compuesto inerte. La capacidad mutagénica de este compuesto reside en su biotransformación y producción de metabolitos de $\mathrm{b}[\mathrm{a}] \mathrm{p}$, principalmente $\mathrm{b}[\mathrm{a}] \mathrm{pDE}$. Los $\mathrm{b}[\mathrm{a}] \mathrm{pDE}$ son considerados metabolitos carcinógenos debido a su capacidad para unirse covalentemente al ADN (formación de aductos) en los grupos amino de la posición C6 de la adenina o C2 de la guanina $(\text { Figura } 4)^{82,83}$. Si estos aductos no son reparados pueden causar mutaciones en genes capaces de conducir a una transformación celular. Un ejemplo clásico de ello son los aductos de b[a]pDE que se han encontrado en sitios específicos dentro de la secuencia del gen TP53 $3^{84}$. Los aductos de b[a]pDE en proteínas, como la hemoglobina, son considerados marcadores de exposición. Por otro lado, se ha reportado que la formación de aductos se correlaciona con aspectos como: el tabaquismo, sexo, presencia de polimorfismos en genes que codifican enzimas que participan en la reparación de daño al $\mathrm{ADN}$, la elevada expresión de enzimas metabolizadoras de carcinógenos y el riesgo de cáncer de pulmón ${ }^{85,86}$.

La actividad carcinogénica y mutagénica del b[a]pDE se le atribuye a la presencia del epóxido en la posición C-10, también llamada región bahía (Figura 4$)^{87}$. Por otro lado, también se pueden formar metabolitos fenólicos directamente por una hidroxilación en la posición C-3 y C-6 del b $[\mathrm{a}] \mathrm{p}^{88}$. Los 6-OH-b[a]p son oxidados por peroxidasas o CYP450 para formar cationes tóxicos 6-oxi-b[a]p que posteriormente son oxidados en posición 1,6-3,6- ó 6,12-vía hidroquinonas o semiquinonas $\mathrm{y}$, de esta manera, formar quinonas ${ }^{89,90}$. Estas quinonas no son mutagénicas, pero las especies reactivas generadas por sus intermediarios son responsables de sus efectos tóxicos ${ }^{91,92}$.

\section{El AhR COMO MEDIADOR eN PROCESOS FISIOLÓGICOS}

Hay trabajos que se han enfocado en estudiar y establecer el papel del AhR como mediador de una respuesta adversa a contaminantes ambientales como el b[a]p. Sin embargo, el alto grado de conservación del AhR en muchas especies animales sugiere que éste podría tener funciones independientes a la del metabolismo de los xenobióticos ${ }^{15}$. De hecho, la participación del AhR en procesos del desarrollo se propuso por los patrones de expresión del AhR y del ARNT observados durante la embriogénesis del ratón ${ }^{93}$. Por otro lado, se ha relacionado al AhR con los procesos celulares de proliferación, apoptosis, diferenciación y promoción de tumores, además, de participar en procesos relacionados con los sistemas inmune y de reproducción. Estas funciones podrían estar relacionadas con la presencia de compuestos endógenos como la bilirrubina ${ }^{27}$, lipoxina $\mathrm{A} 4{ }^{28}$, y derivados del triptófano ${ }^{29}$ que podrían funcionar como ligandos del AhR. Finalmente, los trabajos realizados con ratones carentes del AhR por tres grupos independientes ${ }^{94-96}$, apoyan la idea de la participación del AhR en la homeostasis y el desarrollo.

\section{LOS RECEPTORES ERBB}

Los receptores ErbB son receptores presentes en la membrana celular que convierten señales extracelulares en una respuesta biológica $^{97,98}$. El factor de crecimiento epidermal (EGF) y los factores de crecimiento similares al EGF son proteínas extracelulares que funcionan como ligandos de este tipo de receptores. Los motivos estructurales en común que caracterizan los receptores ErbB son: un dominio extracelular de unión a ligando, un dominio transmembranal hidrofóbico y un dominio citoplasmático con actividad de cinasa de tirosinas ${ }^{97}$. Uno de los receptores ErbB más estudiados es el receptor ErbB-1, también conocido como receptor del factor de crecimiento epidermal (EGFR). Este receptor es activado por la unión del EGF o factores de crecimiento relacionados, como el factor de crecimiento transformante $\alpha$ (TGF- $\alpha$ ), anfiregulina (AREG), epiregulina (EREG) o el factor de crecimiento parecido al EGF de unión a heparina, entre otros ${ }^{99}$. La unión de estos ligandos permite la homo o heterodimerización de los receptores ErbB, lo que resulta en la estimulación de la actividad intrínseca de cinasa de tirosina, la cual consiste en la fosforilación de residuos de tirosina presentes en el dominio citoplasmático del receptor ${ }^{100}$. Estos dominios fosforilados funcionan como sitios de acoplamiento para moléculas de señalización similares a adaptadores los cuales activan directamente las principales vías de transducción de señales en la célula. Por lo tanto, traducen una señal determinada en una respuesta biológica. Subsecuentemente, las señales inducidas son atenuadas mediante la internalización de las moléculas de factores de crecimiento ${ }^{101}$. Esta vía de señalización está involucrada en la regulación de varios procesos celulares como la proliferación, diferenciación y migración. $\mathrm{Su}$ expresión es anormalmente elevada en la mayoría de los cánceres relacionados con células epiteliales ${ }^{102}$. La administración exógena de factores de crecimiento tiene efectos biológicos adversos como la síntesis de ácidos grasos ${ }^{103}$, inhibición de la fusión del paladar ${ }^{104} \mathrm{o}$ la promoción de tumores en la piel ${ }^{105}$. 


\section{Activación de la Vía del AhR y su intercomunicación CON LA VÍA DE RECEPTORES TIPO ERBB}

Existe evidencia de que los efectos causados por TCDD son similares a los efectos causados por el EGF ${ }^{106-109}$. Esto sugiere que el TCDD (sin ser un ligando del EGFR) y el EGF afectan las mismas estructuras celulares. Los primeros indicios de la interferencia del TCDD con la vía de señalización delEGF son los resultados reportados por Madhukar et al. ${ }^{110}$ quienes compararon los efectos adversos de la administración del TCDD con el EGF en un modelo de ratón y observaron que animales expuestos al TCDD y al EGF tuvieron una apertura temprana de los párpados, erupción prematura de piezas dentales y reducción del peso corporal y del timo. A nivel celular, los autores observaron un aumento en la actividad de proteínas cinasas acompañado de una disminución en la capacidad del EGFR para unir el EGF marcado radioactivamente ${ }^{110}$. Estos resultados indicaron, por primera vez, que de alguna manera el TCDD es capaz de activar la vía de señalización mediada por el EGF, lo cual puede ser una explicación de los efectos pleiotrópicos causados por una exposición a este xenobiótico. Estudios posteriores in vivo e in vitro demostraron que la exposición al TCDD incrementa la actividad de proteínas cinasas, particularmente la proteína cinasa $\mathrm{C}(\mathrm{PKC})$ y proteínas cinasas de tirosinas ${ }^{111-113}$. Posteriormente, se demostró que los efectos mencionados también se pueden presentar en tejidos pancreáticos y adipocitos. Por lo tanto, los efectos no están restringidos a tejidos hepáticos ${ }^{114,115}$. Una explicación lógica de este fenómeno podría ser que el TCDD de alguna manera activa al EGFR de forma similar a como lo hace el EGF ${ }^{116,117}$. Sin embargo, el TCDD no es un ligando del EGFR. No obstante, la exposición al TCDD conlleva a alteraciones en los niveles del TGF- $\alpha$, un ligando conocido del EGFR, como lo mencionan Choi et a $l^{118}$ y Gaido et al ${ }^{119}$ donde demostraron que en queratinocitos humanos que fueron expuestos al TCDD se encontró un aumento en la expresión del TGF- $\alpha$. En contraste con estos resultados, se ha reportado que el TCDD disminuye la expresión de TGF- $\alpha$ durante la formación del paladar (palatogénesis) $^{120}$. Los experimentos realizados por Enan y Matsumura $^{34}$ apoyan la idea de que debe existir una segunda vía de señalización dependiente del AhR distinta al modelo clásico, donde la activación del AhR conlleva la activación de genes blanco que cuentan con la secuencia consenso XRE. De esta forma, la identificación de la cinasa de tirosina c-src $\left(\right.$ pp60 $\left.0^{\mathrm{src}}\right)$ como parte del complejo citoplasmático asociado al AhR en su forma inactiva ha contribuido a esclarecer la relación entre la estimulación del EGFR y la vía del AhR y a generar un modelo hipotético por el que estas dos vías interaccionan entre $\mathrm{s}^{335,121}$. La cinasa c-src en su forma soluble es capaz de activar al EGFR mediante la fosforilación de dos residuos específicos de tirosina, lo que resulta en la dimerización del receptor y en la activación de la cascada de señalización ${ }^{122,123}$. Como se ilustra en la figura 6, la unión de un ligando al AhR permite la disociación del complejo citoplasmático al que inicialmente se encuentra unido y la posterior liberación de c-src en el citoplasma ${ }^{121-124}$. La cinasa c-src se transloca a la membrana celular donde puede interactuar con el EGFR de forma bidireccional: la c-src puede unirse y fosforilar al EGFR induciendo así su activación ${ }^{125}$. La relevancia de c-src en la toxicidad mediada por el TCDD se descubrió usando ratones knock-out de c-src. Los ratones knock-out tratados con el TCDD mostraron una disminución de la actividad de la fosfoenolpiruvato carboxicinasa, de la acumulación de triglicéridos, de glicógeno, así como disminución en los efectos tóxicos en el hígado en comparación con los efectos encontrados en los ratones silvestres ${ }^{126-128}$.

La participación de la cinasa c-src en alteraciones celulares promovidas por una exposición al TCDD también se ha observado en líneas celulares. Por ejemplo, en la línea celular derivada de cáncer de mama (MCF10A) el TCDD fue capaz de actuar como antagonista en el crecimiento y la diferenciación celular inducidos por insulina. Mediante el uso de inhibidores farmacológicos, los autores muestran que las propiedades antagónicas del TCDD son mediadas por la activación de la cinasa c-src y de las cinasas extracelulares reguladas por señal 1 y $2(\text { ERK } 1 / 2)^{129}$. Por otro lado, Tannheimer et al.${ }^{130}$ reportaron que los ligandos del AhR, $b[a] p$ y el TCDD fueron capaces de actuar como agonistas en la vía de señalización del factor de crecimiento similar a la insulina en células MCF10A resultando en un aumento en la estimulación del crecimiento celular. Estos trabajos muestran que la exposición a determinados xenobióticos como $b[a] p$ y TCDD induce la activación de las vías de señalización activadas por mitógenos (MAPK), algunas de las cuales forman parte de la vía de señalización del EGFR ${ }^{131-133}$. Por otro lado, se ha reportado que la activación del AhR, además de inducir la transcripción del principal gen en el metabolismo de b[a]p (CYP1A1), también es capaz de inducir la expresión de la ciclooxigenasa-2 (COX-2), la cual se sabe, es dependiente de la activación del EGFR y su vía de señalización es mediada por las MAPK ${ }^{134}$. Estos resultados fueron confirmados usando ratones knock-out para el gen del AhR donde se muestra una disminución en la inducción de los mRNA de COX-2 y CYP1A1 posterior a un estrés inducido por radiación UV-B. Estos datos sugieren que el AhR, CYP1A1 y COX-2, están involucrados en procesos carcinogénicos en la piel ${ }^{134-136}$. Otro equipo de investigación reportó que en macrófagos humanos (THP-1) expuestos al TCDD se induce una sobreexpresión del TNF- $\alpha^{137}$. Los autores argumentan que este incremento se debe a la activación del EGFR y su vía de señalización mediada por ERK 1/2. De manera interesante, en el mismo trabajo fue posible bloquear la expresión del TNF- $\alpha$ con el compuesto a naftoflavona ( $\alpha-\mathrm{NF})$, un antagonista del AhR. Sin embargo, no se logró este mismo resultado usando un inhibidor conocido de la cinasa c-src (PP2). Por lo tanto, este resultado sugiere que posiblemente exista otro mecanismo celular que permita la interconexión de la vía de señalización del AhR con la cascada de señalización del EGFR. Un posible mecanismo puede ser la vía de señalización de la proteína cinasa A (PKA) la cual se sabe, es capaz de regular la transcripción de ampiregulina (AREG) que es un ligando del EGFR ${ }^{138}$. Además, 


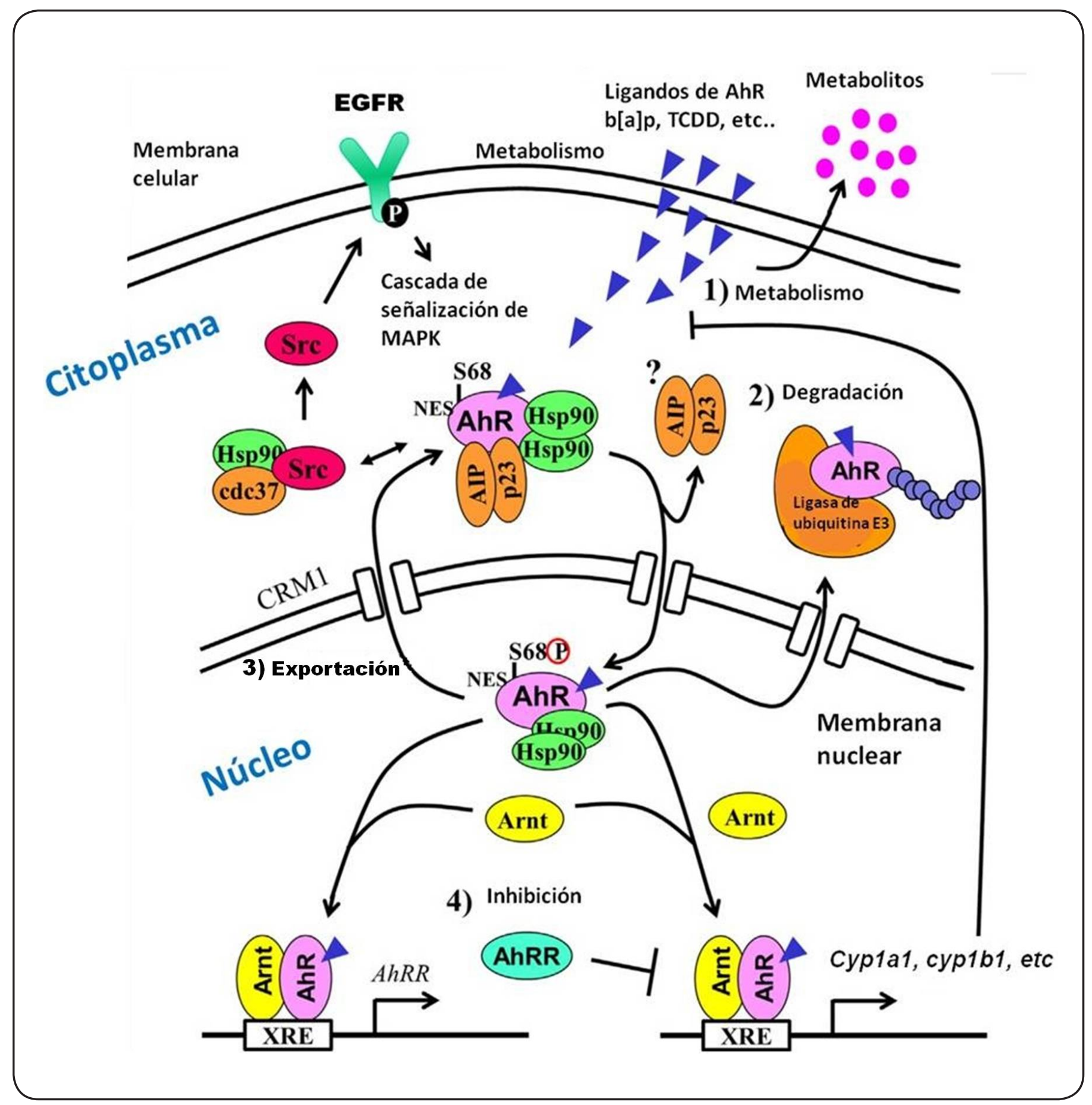

Figura 6. El AhR y su intercomunicación con el EGFR. La interacción entre el AhR y su ligando permite su translocación al núcleo y la liberación de las proteínas a las cuales se encontraba asociado. Ya en el núcleo, el AhR dimeriza con la proteína del ARNT e induce la transcripción de genes blanco. Por su parte, la proteína c-src fosforila al EGFR, iniciando así la cascada de señalización mediada por MAPK. La actividad del AhR es regulada por: (1) la biotransformación del ligando por medio de enzimas metabolizadoras de xenobióticos, (2) la degradación del AhR dependiente del proteosoma 26S, (3) la exportación del AhR del núcleo, y (4) la inducción de la proteína represora de los AhRR. Elementos que se muestran en la figura: AhRR, represor del receptor de hidrocarburos de arilo; AIP, proteína integradora del receptor de hidrocarburos de arilo; Arnt, translocador nuclear del receptor de hidrocarburos de arilo; Cdc37, Proteína del ciclo de división celular 37; Cypla1, citocromo P4501A1; Hsp90, proteína de choque térmico de $90 \mathrm{KDa}$; MAPK, proteínascinasas activadas por mitógenos; NES, señal de exportación nuclear; p23, proteína chaperona de Hsp90 de 23 KDa; S68, serina 68; Src, proteína cinasa de tirocinas Src; XRE, elemento de respuesta a xenobióticos. Modificado de Hao y Whitelaw ${ }^{139}$. 
la exposición de células epiteliales orales a extractos de humo de tabaco induce la señalización mediada por cAMP/PKA y la activación de las proteínas de unión a los elementos de respuesta a cAMP (CREB), resultando en un incremento de los mRNA de $\mathrm{AREG}^{140}$. Interesantemente, en células pre tratadas con $\alpha$-NF, la inducción de AREG promovida por el humo de tabaco es nula.

El hecho de que PKA promueve la activación de la vía del EGFR podría significar una conexión independiente de la cinasa c-src entre de las vías de AhR y el EGFR ${ }^{141}$. En líneas celulares de ratón y otros murinos, el TCDD induce la expresión de los ligandos del EGFR, AREG y epiregulina (EREG) de una forma dependiente del AhR/XRE ${ }^{142,143}$. Patel y su equipo de trabajo identificaron un XRE funcional en el promotor de la EREG en murinos, el cual no tiene homología con el gen en los humanos. Sin embargo, y con base en estos datos, se podría especular que la sobreexpresión de los ligandos del EGFR como la EREG y la AREG inducidos por el TCDD podría causar una activación autocrina retrasada del EGFR, que podría explicar la activación del EGFR mediada por el AhR en presencia del inhibidor de c-src. Por lo tanto, la conexión entre estas tres vías de señalización (AhR, c-src y el EGFR), puede representar un complejo de señalización por el cual compuestos como el b[a]p podrían ser capaces de interactuar con receptores tipo ErbB y, de esta manera desencadenar alteraciones en procesos celulares relacionados con el cáncer.

\section{Conclusiones}

Los trabajos reportados sobre la interacción del AhR con la vía del EGFR muestran la importancia de esta intercomunicación en procesos de estrés celular mediados por la exposición a xenobióticos. Adicionalmente, la sobreexpresión del AhR y del EGFR presente en algunos tumores como los de mama y de pulmón hace evidente la importancia de conocer los detalles de los mecanismos moleculares con miras al desarrollo de nuevas estrategias preventivas y terapéuticas contra enfermedades como el cáncer. Adicionalmente, se debe enfatizar que la mayoría de los estudios se han realizado con líneas celulares derivadas del cáncer o líneas celulares que no corresponden a los tejidos blanco de los compuestos estudiados o de sus metabolitos. Esto implica que en los modelos celulares derivados del cáncer existen alteraciones en la regulación de su ciclo celular y no poseen los elementos celulares necesarios para un correcto metabolismo de los compuestos estudiados. Para una mejor comprensión de las vías de señalización involucradas en procesos de biotransformación y su posible relación con procesos carcinogénicos, los trabajos deben ser realizados en células no transformadas, que cuenten con un sistema de biotransformación funcional y que el modelo corresponda al órgano blanco del compuesto estudiado.

\section{Agradecimientos}

Al Programa de Doctorado en Ciencias Biomédicas de la Universidad Nacional Autónoma de México. Al Consejo nacional de Ciencia y Tecnología (CONACyT) por la beca otorgada para los estudios de doctorado de Gerardo Vázquez Gómez (No. de becario 233838).

\section{Referencias}

1. Hecht, S. Tobacco carcinogens, their biomarkers and tobacco-induced cancer. Nature Reviews Cancer. 3: 733-744 (2003).

2. Vogelstein, B., Papadopoulous, N., Velculescu, V., Zhou, S., Díaz, L. \& Kinzler, K. Cancer genome landscapes. Science. 339: 1546-1558 (2013).

3. Hoffman, E., et al. Cloning of a factor required for activity of the Ah (dioxin) receptor. Science. 252: 954-958 (1991).

4. Hogenesch, J., et al. Characterization of a subset of the basic-helixloop-helix-PAS superfamily that interacts with components of the dioxin signaling pathway. The Journal of Biological Chemistry. 272: 8581-8593 (1997).

5. Gu, Y., Hogenesch, J. \& Bradfield, C. The PAS Superfamily: Sensors of Environmental and Developmental Signals. Annual Review of Pharmacology and Toxicology. 40: 519-561 (2000).

6. Wu, D., Potluri, N., Kim, Y.\& Rastinejad, F. Structure and dimerization properties of the aryl hydrocarbon receptor PAS-A domain. Molecular Cell Biology. 33: 4346-4356 (2013).

7. Ema, M., et al. cDNA cloning and structure of mouse putative Ah receptor. Biochemical and Biophysical Research Communications. 184: 246-253 (1992).

8. Burbach, K., Poland, A. \& Bradfield, C. Cloning of the Ahreceptor cDNA reveals a distinctive ligand-activated transcription factor. Proceedings of the National Academy of Sciences. 89: 8185-8189 (1992).

9. Schmidt, J., Carver, L. \& Bradfield, C. Molecular characterization of the murine Ahr gene. Organization, promoter analysis, and chromosomal assignment. The Journal of Biological Chemistry. 268: 22203-22209 (1993).

10. Dolwick, K., Schmidt, J., Carver, L., Swanson, H. \& Bradfield, C. Cloning and expression of a human Ah receptor cDNA. Molecular Pharmacology. 44: 911-917 (1993).

11. Poland, A., Palen, D. \& Glover, E. Analysis of the four alleles of the murine aryl hydrocarbon receptor. Molecular Pharmacology. 46: 915-921 (1994).

12. Chang, C., Smith, D., Prasad, V., Sidman, C., Nebert, D. \& Puga, A. Ten nucleotide differences, five of which cause amino acid changes, are associated with the Ahreceptor locus polymorphism of C57BL/6 and DBA/2 mice. Pharmacogenetics. 3: 312-321 (1993).

13. Carver, L., Hogenesch, J. \& Bradfield, C. Tissue specific expression of the rat Ah-receptor and ARNT mRNAs. Nucleic Acids Research. 22: 3038-3044 (1994).

14. Korkalainen, M., Tuomisto, J. \& Pohjanvirta, R. Restructured transactivation domain in hamsterAH receptor. Biochemical and Biophysical Research Communication. 273: 272-281 (2000).

15. Hahn, M. Aryl hydrocarbon receptors: diversity and evolution. Chemico-Biological Interactions. 141: 131-160 (2002).

16. Kim, E., Hahn, M., Iwata, H., Tanabe, S. \& Miyazaki, N. cDNA cloning of an aryl hydrocarbon receptor from Baikal seals (Phoca sibirica). Marine Environmental Research. 54: 285289 (2002). 
17. Walker, M., Heid, S., Smith, S. \& Swanson, H. Molecular characterization and developmental expression of the aryl hydrocarbon receptor from the chick embryo. Comparative Biochemistry and Physiology part C Toxicology Pharmacology. 126: 305-319 (2000).

18. Karchner, S., Kennedy, S., Trudeau, S. \& Hahn, M. Towards molecular understanding of species differences in dioxin sensitivity: initial characterization of Ah receptor cDNAs in birds and an amphibian. Marine and Environmental Research. 50: $51-56$ (2000).

19. Hahn, M., Karchner, S., Shapiro, M. \& Perera, S. Molecular evolution of two vertebrate aryl hydrocarbon (dioxin) receptors (AHR1 and AHR2) and the PAS family. Proceedings of the National Academy of Sciences. 94: 13743-13748 (1997).

20. Hahn, M. The aryl hydrocarbon receptor: a comparative perspective. Comparative Biochemistry and Physiology part C Toxicology Pharmacology. 121: 23-53 (1998).

21. Butler, R., Kelley, M., Powell, W., Hahn, M. \& Van Beneden, R. An aryl hydrocarbon receptor (AHR) homologue from the soft-shell clam, Mya arenaria: evidence that invertebrate AHR homologues lack 2,3,7,8- tetrachlorodibenzo-p-dioxin and beta-naphthoflavone binding. Gene. 278: 223-234 (2001).

22. Duncan, D., Burgess, E. \& Duncan, I. Control of distal antennal identity and tarsal development in Drosophila by spinelessaristapedia, a homolog of the mammalian dioxin receptor. Genes and Development. 12: 1290-1303 (1998).

23. Micka, J., Milatovich, A., Menon, A., Grabowski. G., Puga, A. \& Nebert, D. Human Ah receptor (AHR) gene: localization to $7 \mathrm{p} 15$ and suggestive correlation of polymorphism with CYP1A1 inducibility. Pharmacogenetics. 7: 95-101 (1997).

24. Tirona, R. \& Kim, R. Nuclear receptors and drug disposition gene regulation. Journal of Pharmaceutical Sciences. 94: 1169$1186(2005)$.

25. Hao, N., Whitelaw, M., Shearwin, K., Dodd, I. \& Chapman-Smith, A. Identification of residues in the N-terminal PAS domains important for dimerization of Arnt and AhR. Nucleic Acids Research. 39: 3695-3709 (2011).

26. Kewley, R., Whitelaw, M. \& Chapman-Smith, A. The mammalian basic helixloop-helix/PAS family of transcriptional regulators. The International Journal of Biochemistry and Cell Biology. 36: 189-204 (2004).

27. Adachi, J., et al. Indirubin and indigo are potent aryl hydrocarbon receptor ligands present in human urine. The Journal of Biological Chemistry. 276: 31475-31478 (2001).

28. Schaldach, C., Riby, J. \& Bjeldanes, L. Lipoxin A4: a new class of ligand for the Ah receptor. Biochemistry. 38: 7594-7600 (1999).

29. Wei, Y., Hellenberg, H., Rannug, U. \& Rannug, A. Rapid and transient induction of CYP1A1 gene expression in human cells by the tryptophan photoproduct 6-formylindolo $[3,2]$ carbazole. Chemico-Biological Interactions. 110:39-55(1998).

30. Denison, M. \& Nagy, S. Activation of the aryl hydrocarbon receptor by structurally diverse exogenous and endogenous chemicals. Annual Review of Pharmacology and Toxicology. 43: 309-334 (2003).

31. Hao, N., Lee, K., Furness, S., Bosdotter, C., Poellinger, L. \& Whitelaw, M. Xenobiotics and loss of cell adhesion drive distinct transcriptional outcomes by aryl hydrocarbon receptor signaling. Molecular Pharmacology. 82: 1082-1093 (2012).

32. Hankinson, O. Why does ARNT2 behave differently from ARNT? Toxicology Sciences. 103: 1-3 (2008).
33. Bersten, D., Sullivan, A., Peet, D. \& Whitelaw, M. bHLH-PAS proteins in cancer. Nature Reviews Cancer. 13: 827-841 (2013).

34. Enan, E. \& Matsumura, F. Evidence for a second pathway in the action mechanism of 2,3,7,8-tetrachlorodibenzo-p-dioxin (TCDD). Significance of Ah-receptor mediated activation of protein kinase under cell-free conditions. Biochemical Pharmacology. 49: 249-261 (1995).

35. Blankenship, A. \& Matsumura, F. 2,3,7,8-Tetrachlorodibenzopdioxin-induced activation of a protein tyrosine kinase, pp60src, in murine hepatic cytosol using a cell-free system. Molecular Pharmacology. 52: 667-675 (1997).

36. Kobayashi, A., Sogawa, K. \& Fujii-Kuriyama, Y. Cooperative interaction between AhR-ARNT and SP1 for the drug-inducible expression of CYP1A1 gene. The Journal of Biological Chemestry. 271: 12310-12316 (1996).

37. Fujii-Kuriyama, Y. \& Mimura, J. Molecular mechanisms of AhR functions in the regulation of cytochrome P450 genes. Biochemical and Biophysical Research Communications. 338: 311-317 (2005).

38. Hankinson, O. The Aril Hydrocarbon Receptor Complex. Annual Review of Pharmacology and Toxicology. 35: 307-340 (1995).

39. Waxman, D. P450 gene induction by structurally diverse xenochemicals: central role of nuclear receptors CAR, PXR, and PPAR. Archives of Biochemistry and Biophysics. 369: 11-23 (1999).

40. Emmons, R., et al. The spineless-aristapedia and tango bHLH-PAS proteins interact to control antennal and tarsal development in Drosophila. Development. 126: 3937-3945 (1999).

41. Huang, X., Powell-Coffman, J. \& Jin, Y. The AHR-1 aryl hydrocarbon receptor and its co-factor the AHA-1 aryl hydrocarbon receptor nuclear translocator specify GABAergic neuron cell fate in $C$. elegans. Development. 131: 819-828 (2004).

42. Qin, H. \& Powell-Coffman, J. The Caenorhabditis elegans aryl hydrocarbon receptor,AHR-1, regulates neuronal development. Developmental Biology. 270: 64-75 (2004).

43. Kawajiri, K. \& Fujii-Kuriyama,Y.Cytochrome P450 gene regulation and physiological functions mediated by the aryl hydrocarbon receptor. Archives of Biochemistry and Biophysics. 464: 207212 (2007).

44. Konig, J., Nies, AT., Cui, Y., Leier, I. \& Keppler, D. Conjugate export pumps of the multidrug resistance protein (MRP) family: localization, substrate specificity, and MRP2-mediated drug resistance. Biochimica et Biophysica Acta. 1461: 377394 (1999).

45. Roberts, B. \& Whitelaw, M. Degradation of the basic helix-loophelix/Per-ARNT-Sim homology domain dioxin receptor via the ubiquitin/proteasome pathway. The Journal of Biological Chemistry. 274: 36351-36356 (1999).

46. Pollenz, R. The aryl-hydrocarbon receptor, but not the arylhydrocarbon receptor nuclear translocator protein, is rapidly depleted in hepatic and nonhepatic culture cells exposed to 2,3,7,8-tetrachlorodibenzo-p-dioxin. Molecular Pharmacology. 49: 391-398 (1996).

47. Davarinos, N. \& Pollenz, R. Aryl hydrocarbon receptor imported into the nucleus following ligand binding is rapidly degraded via the cytosplasmic proteasome following nuclear export. The Journal of Biological Chemistry. 274: 28708-28715 (1999).

48. Berg, P. \& Pongratz, I. Differential usage of nuclear export sequences regulates intracellular localization of the dioxin (aryl hydrocarbon) receptor. The Journal of Biological Chemistry. 
276: 43231-43238 (2001).

49. Mimura, J., Ema, M, Sogawa, K. \& Fujii-Kuriyama, Y. Identification of a novel mechanism of regulation of Ah (dioxin) receptor function. Genes and Development 13: 20-25 (1999).

50. Murray, I., Patterson, A. \& Perdew, H. Aryl hydrocarbon receptor ligands in cancer: friend and foe. Nature Reviews Cancer. 14: 801-814 (2014).

51. Osborn, M. \& Crosby, T. Benzopyrenes. Cambridge Monographs on Cancer Research. Cambridge University Press, Cambridge, pp. 1-323 (1987).

52. Hecht, S. Cigarette smoking and lung cancer: chemical mechanisms and approaches to prevention. The Lancet Oncology. 3: 461469 (2002).

53. Verma, N., Rettenmeier, A. \& Schmitz-Spanke, S. Exposure of primary porcine urothelial cells to benzo(a)pyrene: in vitro uptake, intracellular concentration and biological response. Archives of Toxicology. 86: 1861-1871 (2012).

54. Sun, J., Wolff, R. \& Kanapilly, G. Deposition, retention, and biological fate of inhaled benzo(a)pyrene adsorbed onto ultrafine particles and as a pure aerosol. Toxicology and Applied Pharmacology. 65: 231-244 (1982).

55. Sun, J., Wolff, R., Kanapilly, G. \& McClellan, R. Lung retention and metabolic fate of inhaled benzo(a)pyrene associated with diesel exhaust particles. Toxicology and Applied Pharmacology. 73: 48-59 (1984).

56. Yamazaki, H., Terada, M., Tsuboi, A., Matsubara, C., Hata, T. \& Kakiuchi, Y. Distribution and binding pattern of benzo(a) pyrene in rat liver, lung and kidney constituents after oral administration. Toxicolological and Environmental Chemistry. 15: 71-81 (1987).

57. Kelman, B. \& Springer, D. Movements of benzo[a]pyrene across the hemochorial placenta of the guinea pig. Proceedings of the Society for Experimental Biology and Medicine. 169: 58-62 (1982).

58. Alexandrov, K., Rojas, M. \& Satarug, S. The critical DNA damage by benzo(a)pyrene in lung tissues of smokers and approaches to preventing its formation. Toxicology Letters. 198: 63-68(2010).

59. Rodgman, A., Smith, C. \& Perfetti, T. The composition of cigarette smoke: a retrospective, with emphasis on polycyclic components. Human and Experimental Toxicology. 19: 573595 (2000).

60. Schmidt, J., Su, G., Reddy, J., Simon, C. \& Bradfield, C. Characterization of a murine Ahr null allele: Involvement of the Ah receptor in hepatic growth and development. Proceddings of the National Academy of Sciences. 93: 6731-6736 (1996).

61. Kapitulnik, J., Wislocki, P., Levin, W., Yagi, H., Jerina, D. \& Conney, A. Tumorigenicity studies with diol-epoxides of benzo (a) pyrene which indicate that $(+/-)$-trans- 7 beta, 8 alpha-dihydroxy-9 alpha, 10 alpha-epoxy-7, 8, 8, 10- tetrahy drobenzo[a]pyrene is an ultimate carcinogen in newborn mice. Cancer Research. 38: 354-358 (1978).

62. Lavin, W., Wood, A., Yagi, H., Jerina, D. \& Conney, A. (+/)trans-7,8-dihydroxy-7,8 dihydrobenzo[a]pyrene: a potent skin carcinogen when applied topically to mice. Proceedings of the National Academy of Sciences. 73: 3867-3871 (1976).

63. Ling, H., et al. Crystal structure of a benzo[a]pyrene diol epoxide adduct in a ternary complex with a DNA polymerase. Proceedings of the National Academy of Sciences. 101: 2265 2269 (2003).

64. Shimada,T.Xenobiotic-Metabolizing Enzymes Involved inActivation and Detoxification of Carcinogenic Polycyclic Aromatic Hydrocarbons. Drug metabolism and pharmacokinetics. 21: 257-276 (2006).

65. Rushmore, T. \& Kong, A. Pharmacogenomics, regulation and signaling pathways of phase I and II drug metabolizing enzymes. Current Drug Metabolism. 3: 481-490 (2002).

66. Weinshilboum, R., Otterness, D., Aksoy, I., Wood, T., Her, C. \& Raftogianis, R. Sulfotransferase molecular biology: cDNAs and genes. The FASEB Journal. 11: 3-14 (1997).

67. Mackenzie, P., et al. The UDP glycosyltransferase gene superfamily: recommended nomenclature update based on evolutionary divergence. Pharmacogenetics. 7: 255-269 (1997).

68. Tukey, R. \& Strassburg, C. Human UDP-glucuronosyltransferases: metabolism, expression, and disease. Annual Review of Pharmacology and Toxicology. 40: 581-616 (2000).

69. Jaiswal, A. Jun and Fos regulation of $\mathrm{NAD}(\mathrm{P}) \mathrm{H}$ : quinone oxidoreductase gene expression. Pharmacogenetics. 4: 1-10 (1994).

70. Guenthner, T. Epoxide Hydrolase. In: G. Mulder (ed.) Conjugation Reactions in Drug Metabolism (London. Taylor \& Francis, 1990). pp. 365-404.

71. Rushmore, T., Pickett, C. \& Lu, A. Xenobiotic and antioxidant induction of the Ya subunit Gene. Berlin Heidelberg: SpringerVerlag. p. 79-107 (1994).

72. Vatsis, K.P., et al. Nomenclarure for N-acetyltransferases. Pharmacogenetics. 5: 1-17 (1995).

73. Weng, M., et al. Alleviation of benzo[a]pyrene-diolepoxide-DNA damage in human lung carcinoma by glutathione $\mathrm{S}$-transferase M2. DNA Repair. 4: 493-502 (2005).

74. Sherratt, P.J., Pulford, D.J., Harrison, D.J., Green, T. \& Hayes, J.D. Evidence that human class Theta glutathione S-transferase T1-1 can catalyse the activation of dichloromethane, a liver and lung carcinogen in the mouse. Comparison of the tissue distribution of GST T1-1 with that of classes Alpha, Mu and Pi GST in human. Biochemical Journal. 326: 837-846 (1997).

75. Sundberg, K., Widersten, M., Seidel, A., Mannervik, B. \& Jernstrom, B. Glutathione conjugation of bay- and fjord-region diol epoxides of polycyclic aromatic hydrocarbons by glutathione transferases M1-1 and P1-1. Chemical Research Toxicology. 10: 1221-1227 (1997).

76. Robertson, I., Guthenberg, C., Mannervik, B. \& Jernstrom, B. Differences in stereoselectivity and catalytic efficiency of three human glutathione transferases in the conjugation of glutathione with 7 beta, 8 alpha-dihydroxy- 9 alpha, 10 alphaoxy-7,8,9,10- tetrahydrobenzo[a]pyrene. Cancer Research. 46: 2220-2224 (1986a).

77. Hu, X., et al. Mechanism of differential catalytic efficiency of two polymorphic forms of human glutathione S-transferase P1-1 in the glutathione conjugation of carcinogenic diol epoxide of chrysene. Archives of Biochemistry and Biophysics. 345: 32-38 (1997).

78. Hayes, J. \& Pulford, D. The glutathione S-transferase supergene family: regulation of GST and the contribution of the isoenzymes to cancer chemoprotection and drug resistance. Critical Reviews in Biochemistry and Molecular Biology. 30: 445-600 (1995).

79. Robertson, I., Jensson, H., Mannervik, B. \& Jernstrom, B. Glutathione transferases in rat lung: the presence of transferase $7-7$, highly efficient in the conjugation of glutathione with the carcinogenic ( + )- 7 beta, 8 alpha-dihydroxy- 9 alpha, 10 alphaoxy-7,8,9,10- tetrahydrobenzo[a]pyrene. Carcinogenesis. 7: 
295-299 (1986b).

80. Mannervik, B. \& Danielson, U. Glutathione transferases - structure and catalytic activity. CRC Critical Reviews in Biochemistry. 23: 283-337 (1988).

81. Sundberg, K., et al. Differences in the catalytic efficiencies of allelic variants of glutathione transferase P1-1 towards carcinogenic diol epoxides of polycyclic aromatic hydrocarbons. Carcinogenesis. 19: 433-436 (1998).

82. Slaga, T., et al. Marked differences in the skin tumor-initiating activities of the optical nantiomers of the diastereomeric benzo(a)pyrene 7,8-diol-9,10-epoxides. Cancer Research. 39: 67-71 (1979).

83. Thakker, D., et al. Metabolism of benzo[a]pyrene VI. Stereoselective metabolism of benzo[a]pyrene and benzo[a]pyrene 7, 8dihydrodiol to diol epoxides. Chemico-Biological Interactions. 16: 281-300 (1977).

84. Dennissenko, M., Pao, A., Tang, M. \& Pfeifer, G. Preferential formation of benzo[a]pyrene adducts at lung cancer mutational hot spots in P53. Science. 274: 430-432 (1996).

85. Phillips, D. Smoking-related DNA and protein adducts in human tissues. Carcinogenesis. 23: 1979-2004 (2002).

86. Mollerup, S., et al. Sex differences in risk of lung cancer: expression of genes in the PAH bioactivation pathway in relation to smoking and bulky DNA adducts. International Journal of Cancer. 119: 741-744 (2006).

87. Phillips, D., et al. Relationship between mutagenicity and DNA adduct formation in mammalian cells for fjord- and bay-region diolepoxides of polycyclic aromatic hydrocarbons. ChemicoBiological Interactions. 80: 177-186 (1991).

88. Gelboin, H. Benzo[alpha]pyrene metabolism, activation and carcinogenesis: role and regulation of mixedfunction oxidases and related enzymes. Physiologycal Reviews. 60: 1107-1166 (1980).

89. Cavalieri, E. \& Rogan, E. The approach to understanding aromatic hydrocarbon carcinogenesis. The central role of radical cations in metabolic activation. Pharmacology and Therapeutics. 55: 183-199 (1992).

90. Sullivan, P. Free radicals of benzo(a)pyrene and derivatives. Environmental Health Perspectives. 64: 283-295 (1985).

91. Wislocki, P., et al. Mutagenicity and cytotoxicity of benzo(a)pyrene arene oxides, phenols, uinones, and dihydrodiols in bacterial and mammalian cells. Cancer Research.36: 3350-3357 (1976).

92. Zhu, H., Li, Y. \& Trush, M. Characterization of benzo[a]pyrene quinone-induced toxicity to primary cultured bone marrow stromal cells from DBA/2 mice: potential role of mitochondrial dysfunction. Toxicology and Applied Pharmacology. 130: 108-20 (1995).

93. Abbott, B., Birnbaum, L. \& Perdew, G. Developmental Expression of Two Members of a New Class of Transcription Factors: I. Expression of Aryl Hydrocarbon Receptor in the C57BL/6N Mouse Embryo. Developmental Dynamics. 204: 133-143 (1995).

94. Fernández-Salguero, P., et al. Inmune system impairment and hepatic fibrosis in mice lacking the dioxin-binding Ah receptor. Science. 268: $722-726$ (1995).

95. Schmidt, J. \& Bradfield, C. Ah receptor signaling pathways. Annual Review of Cell and Developmental Biology. 12: 55-89 (1996).

96. Mimura, J., et al. Loss of teratogenic response to 2,3,7,8tetrachlorodibenzo-p-dioxin (TCDD) in mice lacking the Ah (dioxin) receptor. Genes Cells. 2: 645-654 (1997).
97. Olayioye, M., Neve, R., Lane, H. \& Hynes, N. The ErbB signaling network: receptor heterodimerization in development and cancer. The EMBO Journal. 19: 3159-3167 (2000).

98. Prenzel, N., Fischer, O., Streit, S., Hart, S. \& Ullrich, A. The epidermal growth factor receptor family as a central element for cellular signal transduction and diversification. EndocrineRelated Cancer. 8: 11-31 (2001).

99. Riese, D. \& Stern, D. Specificity within the EGF family/ErbB receptor family signaling network. Bioessays. 20: 41-48 (1998).

100. Hackel, P., Zwick, E., Prenzel, N. \& Ullrich, A. Epidermal growth factor receptors: critical mediators of multiple receptor pathways. Current Opinion in Cell Biology. 11: 184-189(1999).

101. Wiley, H., Herbst, J., Walsh, B., Lauffenburger, D., Rosenfeld, M. $\&$ Gill, G. The role of tyrosine kinase activity in endocytosis, compartmentation, and down-regulation of the epidermal growth factor receptor. The Journal of Biological Chemistry. 266: 11083-11094 (1991).

102. De Luca, A., et al. The role of the EGFR signaling in tumor microenvironment. Jounal of Cellular Physiology. 214: 559567 (2008).

103. Heimberg, M., Weinstein, I., LeQuire, V. \& Cohen, S. The induction of fatty liver in neonatal animals by a purified protein(EGF) from mouse submaxillary gland. Life Sciences. 4: 1625-1633 (1965).

104. Yamamoto, T., Cui, X. \& Shuler, C. Role of ERK1/2 signaling during EGF-induced inhibition of palatal fusion. Developmental Biology. 260: 512-521 (2003).

105. Rose, S., Stahn, R., Passovoy, D. \& Herschman, H. Epidermal growth factor enhancement of skin tumor induction in mice. Experientia. 32: 913-915 (1976).

106. Gupta, B., Vos, J., Moore, J., Zinkl, J. \& Bullock, B. Pathologic effects of 2,3,7,8-tetrachlorodibenzo-p-dioxin in laboratory animals. Environmental Health Perspectives. 5: 125-140(1973).

107. Poland, A., Palen, D. \& Glover, E. Tumour promotion by TCDD in skin of HRS/J hairless mice. Nature. 300: 271-273 (1982).

108. Abbott, B. \& Birnbaum, L. TCDD exposure of human embryonic palatal shelves in organ culture alters the differentiation of medial epithelial cells. Teratology. 43: 119-132 (1991).

109. Abbott, B., Harris, M. \& Birnbaum, L. Comparisons of the effects of TCDD and hydrocortisone on growth factor expression provide insight into their interaction in the embryonic mouse palate. Teratology. 45: 35-53 (1992).

110. Madhukar, B., Brewster, D. \& Matsumura, F. Effects of in vivoadministered 2,3,7,8-tetrachlorodibenzo-p-dioxin on receptor binding of epidermal growth factor in the hepatic plasma membrane of rat, guinea pig, mouse, and hamster. Proceedings of the National Academy of Sciences. 81: 7407-7411 (1984).

111. Bombick, D., Madhukar, B., Brewster, D. \& Matsumura, F. $\operatorname{TCDD}(2,3,7,8$-tetrachlorodibenzo-p-dioxin) causes increases in protein kinases particularly protein kinase $\mathrm{C}$ in the hepatic plasma membrane of the rat and the guinea pig. Biochemical and Biophysical Research Communications. 127: 296-302 (1985).

112. Bombick, D. \& Matsumura, F. TCDD (2,3,7,8- tetrachlorodibenzop-dioxin) causes an increase in protein tyrosine kinase activities at an early stage of poisoning in vivo in rat hepatocyte membranes. Life Sciences. 41: 429-436 (1987a).

113. Bombick, D. \& Matsumura, F. 2,3,7,8-Tetrachlorodibenzo-pdioxin causes elevation of the levels of the protein tyrosine kinase pp60c-src. Journal of Biochemical Toxicology. 2: 141-154 (1987b).

114. Ebner, K., Matsumura, F., Enan, E. \& Olsen, H. 2,3,7,8- 
Tetrachlorodibenzo-p-dioxin (TCDD) alters pancreatic membrane tyrosine phosphorylation following acute treatment. Journal of Biochemical Toxicology. 8: 71-81 (1993).

115. Enan, E. \& Matsumura, F. Significance of TCDD-induced changes in protein phosphorylation in the adipocyte of male guinea pigs. Journal Biochemical Toxicology. 9: 159-170 (1994).

116. Hunter, T. \& Cooper, J. Protein-tyrosine kinases. Annual Review of Biochemistry. 54: 897-930 (1985).

117. Madhukar, B., Ebner, K., Matsumura, F., Bombick, D., Brewster, D. \& Kawamoto, T. 2,3,7,8-Tetrachlorodibenzo-p-dioxin causes an increase in protein kinases associatedwith epidermal growth factor receptor in the hepatic plasma membrane. Journal of Biochemical Toxicology. 3: 261-277 (1988).

118. Choi, E., Toscano, D., Ryan, J., Riedel, N. \& Toscano Jr, W. Dioxin induces transforming growth factor-alpha in human keratinocytes. The Journal of Biological Chemistry. 266: 9591-9597 (1991).

119. Gaido, K., Maness, S., Leonard, L. \& Greenlee, W. 2,3,7,8Tetrachlorodibenzo-p-dioxin-dependent regulation of transforming growth factors-alpha and -beta 2 expression in a human keratinocyte cell line involves both transcriptional and post-transcriptional control. The Journal of Biological Chemistry. 267: 24591-24595 (1992).

120. Abbott, B. \& Birnbaum, L. TCDD-induced altered expression of growth factors may have a role in producing cleft palate and enhancing the incidence of clefts after coadministration of retinoic acid and TCDD. Toxicology and applied pharmacology. 106: 418-432 (1990).

121. Enan, E. \& Matsumura, F. Identification of c-Src as the integral component of the cytosolic Ah receptor complex, transducing the signal of 2,3,7,8-tetrachlorodibenzo-p-dioxin (TCDD) through the protein phosphorylation pathway. Biochemical Pharmacology. 52: 1599-1612 (1996).

122. Sato, K., Sato, A., Aoto, M. \& Fukami, Y. c-Src phosphorylates epidermal growth factor receptor on tyrosine 845 . Biochemical and Biophysical Research Communication. 215: 1078-1087 (1995).

123. Biscardi, J., Maa, M., Tice, D., Cox, M., Leu, T. \& Parsons, S. c-Src-mediated phosphorylation of the epidermal growth factor receptor on Tyr845 and Tyr1101 is associated with modulation of receptor function. The Journal of Biological Chemistry. 274: 8335-8343 (1999).

124. Kohle, C., Gschaidmeier, H., Lauth, D., Topell, S., Zitzer, H. \& Bock, K. 2,3,7,8- etrachlorodibenzo-p-dioxin (TCDD)mediated membrane translocation of c-Src protein kinase in liver WB-F344 cells. Archives of Toxicology. 73: 152-158 (1999).

125. Belsches, A., Haskell, M. \& Parsons, S. Role of c-Src tyrosine kinase in EGF-induced mitogenesis. Frontier in Biosciences. 2: d501-d518 (1997).

126. Dunlap, D., Moreno-Aliaga, M., Wu, Z. \& Matsumura, F. Differential toxicities of TCDD in vivo among normal, c-src knockout, geldanamycin- and quercetin-treated mice. Toxicology. 135: 95-107 (1999).

127. Dunlap, D. \& Matsumura, F. Analysis of difference in vivo effects of TCDD between c-src +/+ mice, c-src deficient, $-/+$ and -/-B6, 129-Src(tm 1 sor) mice and their wild-type littermates. Chemosphere. 40:1241-1246 (2000).

128. Dunlap, D., Ikeda, I., Nagashima, H., Vogel, C. \& Matsumura, F. Effects of src-deficiency on the expression of in vivo toxicity of TCDD in a strain of c-src knockout mice procured through six generations of backcrossings to C57BL/6 mice. Toxicology. 172: 125-141 (2002).

129. Park, S., et al. TCDD causes suppression of growth and differentiation of MCF10A, human mammary epithelial cells by interfering with their insulin receptor signaling through c-Src kinase and ERK activation. Journal of Biochemical and Molecular Toxicology. 18: 322-331 (2004).

130. Tannheimer, S., Ethier, S., Caldwell, K. \& Burchiel, S. Benzo[a]pyrene and TCDD-induced alterations in tyrosine phosphorylation and insulin-like growth factor signaling pathways in the MCF-10A human mammary epithelial cell line. Carcinogenesis. 19: 1291-1297 (1998).

131. Kwon, M., Jeong, K., Choi, E. \& Lee, B. 2,3,7,8-Tetrachlorodibenzop-dioxin (TCDD)-induced activation of mitogen-activated protein kinase signaling pathway in Jurkat T cells. Pharmacology and Toxicology. 93: 186-190 (2003).

132. Park, S., et al.2,3,7,8-Tetrachlorodibenzo-p-dioxin activates ERK and p38 mitogen-activated protein kinases in RAW 264.7 cells. Anticancer Research. 25: 2831-2836 (2005).

133. Randi, A., Sánchez, M., Álvarez, L., Cardozo, J., Pontillo, C. \& de Pisarev, D. Hexachlorobenzene triggers AhR translocation to the nucleus, c-Src activation and EGFR transactivation in rat liver. Toxicology Letters. 177: 116-122 (2008).

134. Fritsche, E., et al. Lightening up the UV response by identification of the aryl hydrocarbon receptor as a cytoplasmatic target for ultraviolet B radiation. Proceedings of the National Academy of Sciences. 104: 8851-8856 (2007).

135. Pentland, A., Schoggins, J., Scott, G., Khan, K. \& Han, R. Reduction of UV-induced skin tumors in hairless mice by selective COX-2 inhibition. Carcinogenesis. 20: 1939-1944 (1999).

136. Shimizu, Y., et al. Benzo[a]pyrene carcinogenicity is lost in mice lacking the aryl hydrocarbon receptor. Proceeding of the National Academy of Sciences. 97: 779-782 (2000).

137. Cheon, H., et al. Signaling pathway for 2,3,7,8-tetrachlorodibenzopdioxin-induced TNF-alpha production in differentiated THP-1 human macrophages. Experimental and Molecular Medicine. 39: 524-534 (2007).

138. Johansson, C., Yndestad, A., Enserink, J., Ree, A., Aukrust, P. \& Tasken, K. The epidermal growth factor-like growth factor amphiregulin is strongly induced by the adenosine 3', 5'-monophosphate pathway in various cell types. Endocrinology. 145: 5177-5184 (2004).

139. Hao, N. \& Whitelaw, M. The emerging roles of AhR in Physiology and immunity. Biochemical Pharmacology. 86: 561-570(2013).

140. Du, B., Altorki, N., Kopelovich, L., Subbaramaiah, K. \& Dannenberg, A. Tobacco smoke stimulates the transcription of amphiregulin in human oral epithelial cells: evidence of a cyclic AMP-responsive element binding protein-dependent mechanism. Cancer Research. 65: 5982-5988 (2005).

141. Piiper, A., et al. Protein kinase A mediates cAMP-induced tyrosine phosphorylation of the epidermal growth factor receptor. Biochemical and Biophysical Research Communications. 301: 848-854 (2003).

142. Choi, S., Miller, M. \& Harper, P. In utero exposure to 2,3,7,8tetrachlorodibenzo-p-dioxin induces amphiregulin gene expression in the developing mouse ureter. Toxicology Sciences. 94: 163-174 (2006).

143. Patel, R., Kim, D., Peters, J. \& Perdew, G. The aryl hydrocarbon receptor directly regulates expression of the potent mitogen epiregulin. Toxicology Sciences. 89: 75-82 (2006). 